\title{
Daily Recovery Experiences: The Role of Volunteer Work During Leisure Time
}

\author{
Eva J. Mojza, Christian Lorenz, \\ and Sabine Sonnentag \\ University of Konstanz
}

\author{
Carmen Binnewies \\ University of Mainz
}

\begin{abstract}
This study focused on the role of volunteer work for daily recovery from work. In a 1-week diary study with 166 employees, we assessed the amount of time spent on volunteer work during leisure time, and the recovery facets of psychological detachment from work (i.e., mentally switching off from work), mastery experiences (i.e., pursuing challenging activities), and community experiences (i.e., cultivating relationships) every day before participants went to bed. Results from hierarchical linear modeling $(n=529$ days) showed volunteer work during leisure time to be positively related to mastery experiences and community experiences suggesting volunteer work to contribute to successful recovery by creating new resources.
\end{abstract}

Keywords: recovery, psychological detachment from work, mastery experiences, community experiences, volunteer work

One important quality of leisure time is its potential to provide recovery opportunities from stressful work (Zijlstra \& Cropley, 2006). Recovery refers to the process by which individual functional systems that have been called upon during a stressful experience (e.g., during the workday) return to their prestressor level (Meijman \& Mulder, 1998). Successful recovery has been shown to positively affect wellbeing and performance (Binnewies, Sonnentag, \& Mojza, 2009b; Fritz \& Sonnentag, 2005, 2006; Sonnentag \& Bayer, 2005). Several experiences during leisure time contribute to successful recovery: Psychological detachment from work (i.e., switching off mentally from work), mastery experiences (i.e., pursuing challenging activities), and community experiences (i.e., cultivating relationships; Sonnentag \& Fritz, 2007).

Eva J. Mojza, Christian Lorenz, and Sabine Sonnentag, Department of Psychology, University of Konstanz; Carmen Binnewies, Department of Psychology, University of Mainz.

This research was funded by a grant from the German Research Foundation (DFG; SO 295/4-1, 4-2) that is gratefully acknowledged. We thank Claudius Bornemann, Julia Meyer-Schwickerath, and Signe Seiler for their involvement in data collection and Jessica de Bloom, Daniel Fleischer, Verena Friedrich, Charlotte Fritz, Jennifer L. Sparr, and Maya Yankelevich for helpful comments on earlier versions of this paper.

Correspondence concerning this article should be addressed to Eva J. Mojza, Department of Psychology, University of Konstanz, Postbox 42, D-78457 Konstanz, Germany. E-mail: Eva.Mojza@uni-konstanz.de
The purpose of our study is to examine the role of volunteer work, as a specific form of leisure time activity, for the recovery process. Volunteer work needs to come into the focus of occupational health psychologists as it is performed by many people (TNS Infratest, 2007; United States Department of Labor, 2009). Surprisingly, little is known about the potential benefits of volunteer work activities for recovery. Although it is known, for instance, that job-related activities during leisure time are negatively related to psychological detachment from work (Sonnentag \& Bayer, 2005), volunteer work activities during leisure time have not been considered in the context of recovery experiences.

We use the terms work or job to refer to paid work (i.e., work within the occupation); we use volunteer work as referring to volunteer work activities during leisure time. We consider work time as time dedicated to the regular job within the regular working day and at the work place, while leisure time refers to the time one spends off the regular job. Volunteer work refers to "any activity in which time is given freely to benefit another person, group, or cause. Volunteering is a part of a cluster of helping behaviors, entailing more commitment than spontaneous assistance but narrower in scope than the care provided to family and friends" (Wilson, 2000, p. 215). In many countries, a great part of the population engages in volunteer work activities. For example, $26.4 \%$ of the U.S. population volunteered in 2008 (United States Department of Labor, 2009) and 33\% of the European Union population volunteered in 
2006 (TNS Infratest, 2007). Volunteer work has been shown to be positively associated with happiness, life satisfaction, self-esteem, sense of control over life, and physical health and negatively associated with depression (Thoits \& Hewitt, 2001) indicating that volunteer work contributes to one's well-being and could thus be also beneficial for recovery experiences.

Focusing on relationships between volunteer work during leisure time and recovery experiences is consistent with other research efforts that aim at examining activities during leisure time that enhance or impede successful recovery (Fritz \& Sonnentag, 2005; Rook \& Zijlstra, 2006; Sonnentag, 2001; Zijlstra \& Cropley, 2006). Usually working time is regarded as being reserved for work whereas leisure time as being reserved for recovery (Zijlstra \& Cropley, 2006). Therefore, it is important to know if volunteer work during leisure time, which is by definition unpaid work (Bierhoff, 2002) and can be demanding itself (Kinzel \& Nanson, 2000) is associated with experiences that contribute to successful recovery from work. Earlier studies provided empirical evidence for the recovery potential of other demanding activities such as military service (e.g., Etzion, Eden, \& Lapidot, 1998) suggesting that "just doing something different" (e.g., Etzion et al., 1998, p. 584) helps to disengage and to recover from work. Thus, the purpose of our study was to examine if volunteer work during leisure time contributes to successful recovery by assessing the relationships between volunteer work and the recovery experiences of psychological detachment from work, mastery experiences, and community experiences.

In line with other studies that examined recovery experiences from a day-level perspective (Cropley, Dijk, \& Stanley, 2006; Cropley \& Millward Purvis, 2003; Sonnentag \& Bayer, 2005), we conducted a diary study. Thereby, we linked the amount of time spent on volunteer work during the leisure time of a given day to the recovery experiences of the same day, as reported at bedtime. This study design allowed us to examine if differences within individuals (i.e., within-person perspective) with respect to the time spent on volunteer work during one's leisure time contribute to daily fluctuations in psychological detachment from work, mastery experiences, and community experiences.

\section{Recovery Experiences: Psychological Detachment From Work, Mastery Experiences, and Community Experiences}

Psychological detachment from work pertains to an 'individual's sense of being away from the work situation" (Etzion et al., 1998, p. 579). It does not only imply not being occupied with job-related duties (e.g., not answering job-related phone calls at home and refraining from job-related activities after work), but also includes disengaging oneself mentally from work by not cogitating about job-related topics (Sonnentag \& Bayer, 2005). Sonnentag and Fritz (2007) suggested that psychological detachment from work is crucial for recovery because the functional systems called upon during work are relieved. This notion is in line with the Effort-Recovery Model (Meijman \& Mulder, 1998). Meijman and Mulder (1998) essentially propose that recovery from job stress takes place when the source of the stress vanishes. When individuals are not successful in detaching mentally from work and instead keep thinking about their jobs, the identical functional systems are taxed without any break (Sonnentag \& Fritz, 2007), and full recovery is unlikely to occur.

Results from diary and cross-sectional studies show positive associations of psychological detachment from work with several favorable outcomes and negative associations with a number of rather unfavorable outcomes. For example, results from a sample of employees holding a variety of different jobs indicated that psychological detachment from work is positively associated with life satisfaction (Sonnentag \& Fritz, 2007). Moreover, Sonnentag and Bayer (2005) found that individuals who detached successfully from their job after work indicated being in a better mood and experiencing less fatigue at the end of the day. With regard to outcomes of unsuccessful psychological detachment from work, studies indicated negative relationships between psychological detachment from work and health complaints, emotional exhaustion, depressive symptoms, need for recovery, and sleep difficulties (Sonnentag \& Fritz, 2007; Taris, Geurts, Schaufeli, Blonk, \& Lagerveld, 2008). Finally, Etzion et al. (1998) showed participants of a military reservist training in Israel to recover more successfully from job stress and burnout when they detached well from their jobs during the reserve service (i.e., reported little or no thoughts about their regular job) compared to participants who did not detach or who detached less. This finding indicates an additional effect of psychological detachment from work on recovery-beyond the influence of the mere absence of job stressors-as it suggests demanding activities to contribute to recovery as well.

Whereas detachment implies the absence of demands, mastery experiences explicitly pose challenges to individuals: Mastery experiences are de- 
fined as activities that provide learning opportunities or that challenge individuals (Sonnentag \& Fritz, 2007). Examples of such activities comprise new or difficult physical activities (e.g., hiking, skiing, marathon training) or intellectually stimulating activities (e.g., studying a foreign language, learning a new hobby). Although self-regulation and effort are required to engage in mastery activities, because individuals need to overcome impulses to just relax during their leisure time, mastery activities are positively related to recovery for two reasons (Sonnentag \& Fritz, 2007). First, mastery activities create new resources, such as a sense of self-efficacy (Bandura, 1997) and new competencies (Hobfoll, 1989). Second, active or energetic activities, which may be accompanied by mastery experiences, contribute to well-being by enhancing positive mood (Totterdell \& Parkinson, 1999). Zijlstra and Cropley (2006) even proposed that, with respect to the recovery process, it is more valuable to engage in challenging activities that help to develop and cultivate skills than to unwind passively, for example, by watching TV. Accordingly, empirical evidence shows positive associations of mastery experiences and some favorable outcomes and negative associations with unfavorable outcomes. Csikzentmihalyi (1990) showed positive relationships between challenging and skill-forming experiences and well-being. Mastery experiences during a vacation have been found to be negatively associated with emotional exhaustion after the vacation (Fritz \& Sonnentag, 2006). Physical activities, as a specific form of challenging mastery experiences, were shown to be negatively associated with fatigue (Rook \& Zijlstra, 2006) and depression (Sonnentag $\&$ Natter, 2004).

Community experiences refer to activities that provide opportunities for social contacts and connectedness (Sonnentag \& Fritz, 2007) and further imply cultivating relationships (Fritz \& Sonnentag, 2005). Community experiences include meeting with people one likes or pursuing activities together with others (Fritz \& Sonnentag, 2005). Community experiences are important for recovery because they are associated with the gain of resources, in particular social resources such as close relationships with friends or being involved in organizations with other people who share the same interests. Thus, recovery is possible through upholding the network and drawing on social support (Fritz \& Sonnentag, 2005). Research has shown positive relationships between community experiences and favorable outcomes as well as negative relationships between community experiences and unfavorable outcomes. For example, feeing con- nected to others (i.e., to have community experiences) was shown to be fundamental for daily wellbeing (Reis, Sheldon, Gable, Roscoe, \& Ryan, 2000; Sheldon, Ryan, \& Reis, 1996). In another diary study, engaging in social activities during the evening was positively related to well-being before going to bed (Sonnentag, 2001). In addition, community experiences during the weekend were shown to be negatively related to disengagement and poor well-being at the end of the weekend and positively related to task performance on the job after the weekend (Fritz \& Sonnentag, 2005).

\section{Volunteer Work During Leisure Time and Recovery Experiences}

We propose volunteer work during leisure time to be positively related to psychological detachment from work, mastery experiences, and community experiences. Volunteer work during leisure time should be conducive to psychological detachment from work for three reasons. First, we assume individuals being engaged in volunteer work activities to be profoundly involved in this volunteer work and, thus, being distracted from job-related issues. This notion is proposed in the theory of flow. Flow refers to a state in which people are so intensely involved in an activity that nothing else seems to matter (Csikzentmihalyi, 1990). The general assumption of flow theory is that people forget everything around them when they get fully absorbed in an activity (Csikzentmihalyi, 1990). Comparably, being engaged in volunteer work activities during leisure time should prevent people to think about job-related issues. Consequently, psychological detachment from work will be facilitated because volunteer work is associated with cherished experiences, self expression, and a combination of superficial enjoyment and deep satisfaction (Stebbins, 2004), experiences with the potential of absorption.

Moreover, because volunteering activities that are not similar to every day's jobs in all respects, they contribute to psychological detachment from work. The reason for this assumption is that volunteers often operate in a nonwork context with different people than in their paid jobs. Under these circumstances, on-the-job experiences are mentally less accessible than experiences in situations in which one is likely to reflect on one's job (such as being alone while exercising physically).

Second, further support for the assumption that volunteer work contributes to psychological detach- 
ment from work by distracting from job-related issues comes from the literature on affect regulation strategies. People effectively distract themselves by doing something pleasant or performing a demanding activity (i.e., behavioral distraction strategies) to regulate their mood (Totterdell \& Parkinson, 1999). In a similar vein, we propose that when people engage in volunteer work activities during their leisure time-an activity, which on the one hand can be experienced as pleasant and on the other hand is a demanding activity (Schroer \& Hertel, 2009; Stebbins, 2004) — they get distracted from their job and therefore mentally detach from work.

Third, psychological detachment from work is likely to happen during volunteering because of its social nature. Volunteer work by definition includes helping behaviors (Wilson, 2000) and, therefore, often takes place in a social context. We know that people are less occupied by job-related issues when they are together with others than when they are alone (Cropley \& Millward Purvis, 2003). Hence, volunteer work as a social activity should serve as a facilitator for psychological detachment from work.

Hypothesis 1: The amount of time spent on volunteer work activities during leisure time is positively related to psychological detachment from work during evening hours.

Volunteer work activities during leisure time should be positively associated with mastery experiences because volunteer work offers opportunities for learning and for challenging experiences. One important reason for people to engage in volunteer work is to obtain "new learning experiences and the chance to exercise knowledge, skills, and abilities that might otherwise go unpracticed" (Clary et al., 1998, p. 1518). Accordingly, woman managers who engaged in volunteer work activities reported improvements in their interpersonal skills and leadership skills ( $\mathrm{Ru}-$ derman, Ohlott, Panzer, \& King, 2002). Additionally, it is known that, in the end, engagement in volunteer work is positively associated with occupational status (Wilson \& Music, 2003). Volunteer work has the potential to provide learning opportunities for the improvement of job-related skills that in turn results in a favorable career development (Wilson \& Music, 2003), a possible underlying cause of the positive relationship between volunteer work and occupational status. Volunteer work is associated with skill development; hence, we expect daily volunteer work to be positively associated with mastery experiences. Furthermore, volunteer work should offer opportuni- ties for challenges because it is associated with developing and expressing skills, abilities and knowledge (Stebbins, 1996). Challenging activities are a prerequisite for mastery experiences to occur during volunteer work.

Hypothesis 2: Time spent on volunteer work activities during leisure time is positively related to mastery experiences during evening hours.

Volunteer work should be positively related to community experiences for two reasons. First, volunteering often implies pursuing activities with friends. Initially, many volunteers become involved in their volunteer work activities in the social pull of friends or acquaintances who are already engaged in volunteering (von Rosenbladt, 2000). Consequently, many volunteers work together with friends and thereby maintain relationships while volunteering. Additionally, Bierhoff, and Schülken (2001) reported that volunteers made friends during the pursuit of their volunteering activity. Second, volunteer work should be associated with community experiences because individuals with similar interests come together in the field they are engaged in (Bierhoff \& Schülken, 2001; Clary et al., 1998). In the context of environmental protection groups, for example, the leader of such a group as well as the group members are people who have similar connections to the topic (e.g., a passion for nature). Therefore, a similarity is found, communication facilitated, and feelings of connectedness and community experiences are likely to occur. Thus, volunteer work should be associated with community experiences.

Hypothesis 3: Time spent on volunteer work activities during leisure time is positively related to community experiences during evening hours.

\section{Control Variables}

In our study, we controlled for a number of variables that could be associated with psychological detachment from work, mastery experiences, and community experiences: gender, age, number of children, and negative affectivity. Our reason for controlling for demographic data (i.e., gender, age, and number of children) was that women or people with children might differ in their ability to recover (i.e., to detach psychologically from work, to engage in some mastery experiences) because of duties at home or with respect to children. Additionally, older people 
may have more difficulties to switch off from work than younger people or to engage in activities witch are associated with mastery experiences. Because negative affectivity may bias responses in survey studies (Brief, Burke, George, Robinson, \& Webster, 1988), it could have an influence on how people judge their level of psychological detachment, mastery experiences, and community experiences.

On the day-level, we also controlled for variables that could impede recovery experiences, that is, daily working hours and the amount of time spent on job-related activities during leisure time. We also controlled for other leisure times activities, which could be beneficial for recovery experiences, that is, the amount of time spent on physical activities and on social activities, because we wanted to show the benefits of volunteering beyond other leisure time activities. The day-specific work hours could exert an influence on recovery experiences in the sense that on longer working days people have less time to detach from work or are too tired to engage in activities associated with mastery.

\section{Method}

\section{Overview}

Data were collected as part of a project on recovery from work stress (Binnewies, Sonnentag, \& Mojza, 2009a; Sonnentag, Binnewies, \& Mojza, 2008) including a general survey assessing personspecific data and daily surveys administered over the course of one workweek. The general survey was completed mostly 2 weeks before the start of the daily surveys. Then, over the course of five consecutive workdays, handheld computers were used to record day-specific data. Participants responded to items that were specifically relevant to our research questions at two measurement times: first, after returning home from work (after work survey), and second, at night before going to bed (bedtime survey). Because of the research project's design, a third daily measurement time was scheduled in the morning. As the information gathered in the morning was not relevant for our present research questions, subsequent descriptions are based on the measurement times in the afternoon and evening.

\section{Recruiting Procedure and Sample}

Our research team approached managers of city halls and other public administration organizations describing the study's aim and asking for adminis- trative support in recruiting participants. Upon their consent to support our study, information on the research project and conditions for participation were mailed to the employees. Interested employees were provided with the general survey and asked to complete it before the beginning of daily data collection. A date was scheduled to distribute the handheld computers, and participants were trained in using the handheld computer. Two incentives were offered for participation: first, managers and participants were provided organization-specific feedback; second, a weekend in a spa was announced as lottery prize raffled among all participants.

Overall, 203 employees from 36 city halls and other public administration organizations participated in this study. Because of technical problems with the handheld computers, four people could not provide any daily data. From the remaining 199 participants, data from the general survey and the daily survey could be matched for 192 participants. Because 26 participants missed either daily surveys or failed to comply with specific instructions (e.g., the bedtime survey was completed in the morning), they were excluded from analyses, resulting in a final sample of 166 persons.

Of the 166 participants, 104 (62.7\%) were women and $62(37.3 \%)$ were men. Their mean age was 38.64 years $(S D=10.73)$, ranging from 16 to 61 years. With respect to their family and living situation, $53.6 \%$ of the participants reported to be have no children. Of the remaining $45.2 \%$ of the participants, most (53.3\% of the participants with children) had two or more children.

The main job responsibilities of participating employees were local administration and public services. Of our participants, $44.6 \%$ worked primarily in administrative jobs (e.g., civil servants in the local and financial administration of small towns and villages), $21.7 \%$ had higher level administrative jobs (e.g., chief officers of larger administrative units), $12.7 \%$ had jobs in the field of social administration and service (e.g., social workers), $8.4 \%$ had jobs as support staff (e.g., secretaries), 6.0\% had professional jobs in technical and cultural fields (e.g., manager for a town's cultural life), and $6.6 \%$ worked in a variety of other jobs. Participants' average professional experience was 15.03 years $(S D=9.57)$, with an average tenure with their current organization of 9.73 years $(S D=8.11)$. Leadership positions were held by $35.5 \%$ of the participants. Our sample was well educated with $48.2 \%$ of our participants holding a university degree. A further $39.2 \%$ had completed a 2 - to 3 -year professional training program and $8.4 \%$ had 
completed a 2- to 3-year professional training program and gained an additional professional degree. Only $2.4 \%$ of our participants had not finished any professional training. Of our participants, $78.3 \%$ worked in Germany and $21.7 \%$ worked in Switzerland.

On average, participants worked 4.9 days $(S D=$ $0.60)$ per week and completed a total of 36.77 working hours $(S D=6.55)$. In the whole sample $(N=$ 166), we had 61 participants $(36.75 \%)$ who reported to pursue some kind of volunteer work activity on at least on 1 day. When pursuing volunteer work activities, these 61 participants spent a mean of 12.01 $(S D=74.18)$ min per day on volunteer work activities ranging from $10 \mathrm{~min}$ to $8 \mathrm{hr}$. Across all participants, volunteer work activities during leisure time occurred on $99(18.7 \%)$ of the 529 evenings.

\section{Measures}

All questions were presented in German. The measures to capture recovery experiences were developed by German researchers (Fritz \& Sonnentag, 2005; Sonnentag \& Fritz, 2007) and were accessible to us in their original German form. Items to measure recovery experiences were slightly rephrased to suit the format of a daily assessment (i.e., referred to the recovery dimensions experienced during the respective day; Sonnentag et al., 2008). With respect to other measures (i.e., PANAS, see below), we also used a German version that had been validated in earlier research (Krohne, Egloff, Kohlmann, \& Tausch, 1996).

Time spent on volunteer work activities during leisure time was assessed in the bedtime survey with the one-item question "How much time did you spend on volunteer work activities today, for example, in church, political activities?" At the time the handhelds were handed over, research team members carefully and personally instructed the participants to comply with our definition of volunteer work. In addition, we called participants' attention to the fact, that the examples (i.e., church, political activities) only served to illustrate the category of volunteer work activities, however, could not sufficiently cover all associated aspects of it.

Psychological detachment from work was measured with four items adapted from the recovery experiences questionnaire (Sonnentag \& Fritz, 2007) in the bedtime survey. Participants responded to the items on a 5-point Likert scale $(1=$ not true at all; $5=$ very true). A sample item was "Tonight, I distanced myself from my work." Cronbach's alphas, computed separately for the 5 days, ranged from .87 to .93 (mean $\alpha=.90$ ).

Mastery experiences were also measured with four items adapted from the recovery experiences questionnaire (Sonnentag \& Fritz, 2007) in the bedtime survey. Participants responded to items on a 5-point Likert scale $(1=$ not true at all; $5=$ very true $)$. A sample item was "Tonight, I learned new things." Cronbach's alphas for the 5 days ranged from .80 to .88 (mean $\alpha=.83$ ).

Community experiences were measured with three items from Fritz and Sonnentag (2005) and one additional item. Participants responded to items on a 5-point Likert scale ( $1=$ not true at all; $5=$ very true). A sample item was "Tonight, I networked." Cronbach's alphas for the 5 days ranged from .86 to .93 (mean $\alpha=.90$ ).

We computed confirmatory factor analyses with person-centered items (Bolger, Davis, \& Rafaeli, 2003) to check if psychological detachment from work, mastery experiences, and community experiences represented different constructs. Analyses showed a better fit for the three-factor model than for the alternative one-factor model $\left(\Delta \chi^{2}=3,215.77\right.$, $\Delta d f=3, p<.01)$ and all possible two-factor-models $\left(\Delta \chi^{2}\right.$ ranging between 968.83 and 1,998.02, $\Delta d f=2$, $p<.01)$. The fit indices for the three-factor model were good $(\mathrm{RMSEA}=.053, \mathrm{CFI}=.98, \mathrm{NFI}=.97$, $\mathrm{GFI}=.97)$ indicating that the recovery experiences psychological detachment from work, mastery experiences, and community experiences could be distinguished at the construct level.

Control variables. Control variables at the person level were assessed in the general survey. We included the single item measures of gender $(1=$ women, $2=$ men), age, and the number of children. Furthermore, negative affectivity was assessed using six items of the PANAS questionnaire (Krohne et al., 1996; Watson, Clark, \& Tellegen, 1988). Participants responded to items on a 5-point Likert scale $(1=$ not at all to $5=$ very much). Cronbach's alpha was .77 . As a control variable at the day level we assessed the amount of working hours by a single item ("How long did you work today?") in the after-work survey. Other control variables at the day level (i.e., jobrelated activities during leisure time, physical activities during leisure time, and social activities during leisure time) were assessed with one-item questions in the bedtime survey. The questions assessed the amount of time spent on each activity during leisure time: "How much time did you spend on workrelated activities today, for example, completing a task, private paperwork, preparation for the next 
working day?," "How much time did you spend on physical activities today, for example, sports, cycling, bodybuilding?," and "How much time did you spend on social activities today, for example, meeting friends or relatives, going out, talking with your partner or roommates?" Participants were specifically instructed to assign every activity they had pursued during the day only once and to the one category of activities that was the most salient one to them. For example, we required persons who volunteered as soccer coaches to indicate volunteering if they perceived their activity mainly as contributing to the good cause and as physical activity if they did it mainly to play sports. Table 1 displays means, standard deviations, and correlations between study variables.

\section{Results}

\section{Data Preparation and Preliminary Analyses}

As our data holds a hierarchical structure with days (Level 1) nested within persons (Level 2), we used a hierarchical modeling approach. Computations were executed with the MLwiN software (Rasbash, Steele, Browne, \& Prosser, 2004). Person-specific data (i.e., information about gender, age, number of children, leadership position, and negative affectivity), assessed with the general questionnaire, constituted Level 2 data, whereas day-specific data (i.e., working hours, job stressors, leisure time activities, and recovery experiences), recorded on a daily basis, constituted Level 1 data. Level 2 data were centered around the grand mean, whereas Level 1 predictor variables were centered around the respective person mean.

To check whether hierarchical linear modeling was appropriate for our data we examined if psychological detachment from work, mastery experiences, and community experiences differed within persons. We partitioned the total variance into within-individual and between-individual variance. For psychological detachment from work within-individual variance was $57.9 \%$ (Level 1 intercept variance, i.e., 0.6036 divided by total variance, i.e., $0.6036+0.4393$, cf. Table 2), for mastery experiences within-individual variance was $74.8 \%$, and for community experiences within-individual variance was $74.4 \%$. Accordingly, a substantial portion of the variance can be attributed to variance within persons suggesting that hierarchical linear modeling is suitable.

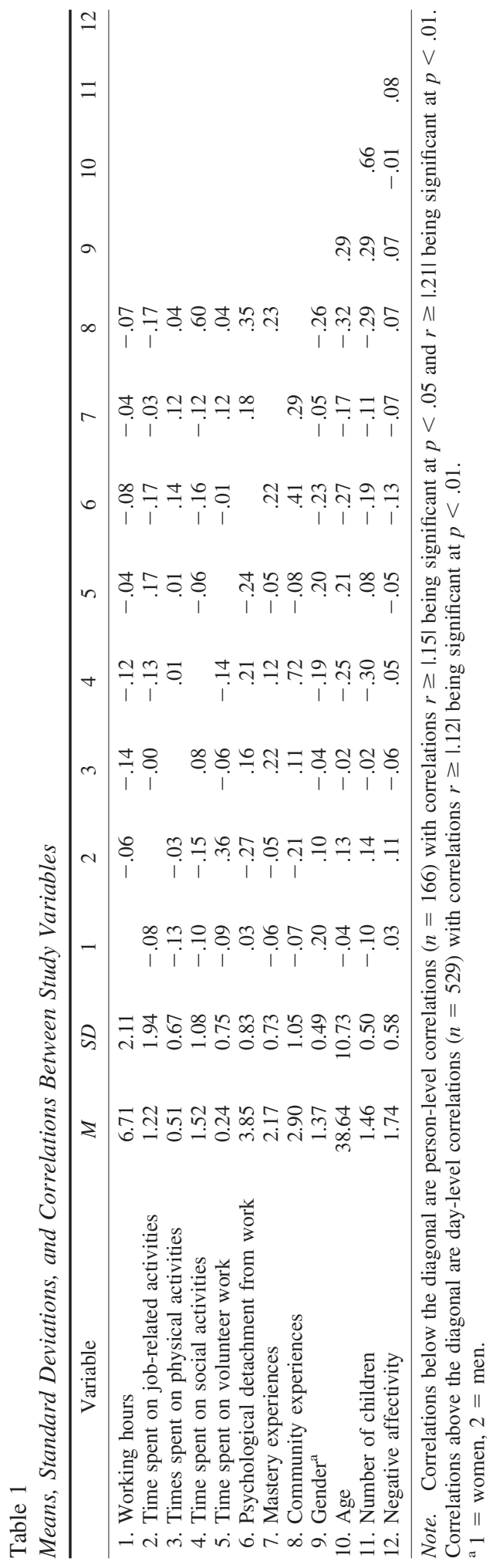




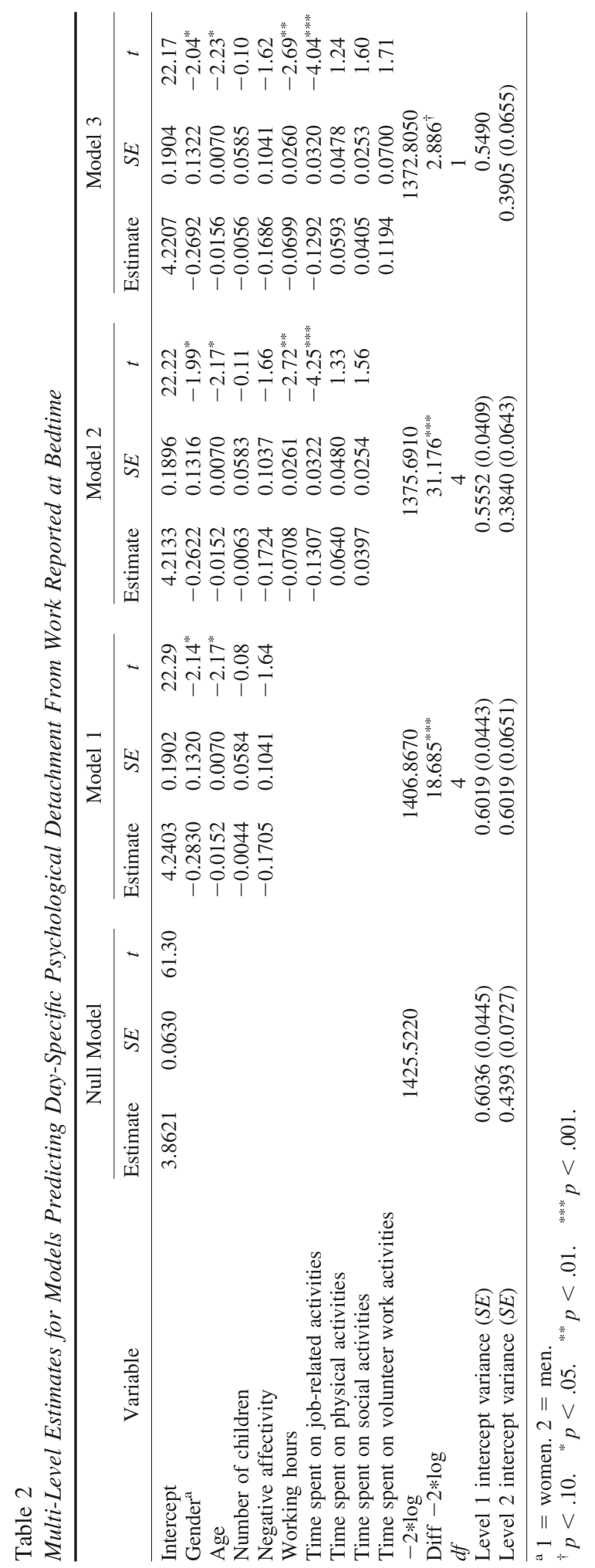




\section{Test of Hypotheses}

To test our hypotheses we ran several models for the three outcome variables psychological detachment from work, mastery experiences, and community experiences. In the Null Model, we included only the intercept. In Model 1, we included the control variables at the person level (i.e., gender, age, number of children, and negative affectivity). In Model 2, we entered control variables at the day level (i.e., working hours during the workday, time spent on job-related activities, time spent on physical activities, and time spent on social activities during leisure time). Finally, in Model 3 we included the predictor, that is, time spent on volunteer work activities during leisure time. To examine the improvement of each model over the previous one we calculated the differences between the respective likelihood statistics and tested them with $\chi^{2}$ difference-tests.

Table 2 shows the results of the multilevel analysis for psychological detachment from work reported at bedtime. Model 1 showed significant improvement over the Null Model $(\Delta-2 \times \log =18.685, d f=4$, $p<.001)$. Gender and age were both significant predictors for psychological detachment from work reported at bedtime indicating that women detached less than men and older people detached less than younger people from work. Model 2 showed further improvement over Model $1(\Delta-2 \times \log =31.176$, $d f=4, p<.01)$. The number of working hours during the work day was negatively related to psychological detachment from work reported at bedtime indicating that the more hours participants worked during the day, the less they could detach themselves from work during leisure time. In addition, the number of hours spent on job-related activities during leisure time was negatively related to psychological detachment from work reported at bedtime. Model 3 showed only a marginal significant improvement over Model $2(\Delta-2 \times \log =2.886$, $d f=1, p=.09$ ), time spent on volunteer work during leisure time was not a predictor for psychological detachment from work. Thus, we found no support for Hypothesis 1.

Table 3 shows the results of the multilevel analysis for mastery experiences reported at bedtime. Model 1 did not show improvement over the Null Model ( $\Delta-$ $2 \times \log =5.238, d f=4, n s)$; and Model 2 did not show improvement over Model $1(\Delta-2 \times \log =$ $3.314, d f=4, n s)$. Model 3 showed significant improvement over Model $2(\Delta-2 \times \log =7.968, d f=$ $1, p<.05)$. Supporting Hypothesis 2, number of hours spent on volunteer work was a significant predictor for mastery experiences reported at bedtime.

Table 4 shows the results of the multilevel analysis for community experiences reported at bedtime. Model 1 showed improvement over the Null Model $(\Delta-2 \times \log =20.183, d f=4, p<.01)$. Model 2 showed further improvement over Model $1(\Delta-2 \times$ $\log =155.19, d f=4, p<.01)$. Time spent on job-related activities during leisure time was a significant negative predictor, whereas time spent on social activities was a significant positive predictor for community experiences. Model 3 showed further improvement over Model $2(\Delta-2 \times \log =7.358$, $d f=1, p<.05)$. Time spent on volunteer work during leisure time was a significant predictor for community experiences, thus supporting Hypothesis 3. Taken together, results from multilevel analyses indicated that volunteer work during leisure time was positively associated with mastery and community experiences. ${ }^{1}$

\section{Discussion}

In our diary study, we established positive relationships between time spent on volunteer work and two important recovery experiences: mastery experiences and community experiences. The results suggest that volunteer work activities during leisure time offer learning possibilities and provide opportunities to master challenges as well as possibilities to cultivate relationships. In terms of recovery, it seems that volunteer work predominantly contributes to recovery by creating new resources. Mastery experiences include the gain of resources such as new competencies, whereas community experiences include the gain of new resources such as close relationships. These results become even more interesting when considering that other leisure time activities (i.e., those we measured here as control variables) did not show many relationships with recovery experiences. For example, physical activities were neither related to psychological detachment from work, nor related to mastery experiences, or to community experiences. Thus, when considering relationships between physical activities and recovery experiences, it might be that it is rather the specific kind of physical activ-

\footnotetext{
${ }^{1}$ We conducted additional analyses excluding days with extremely high scores of voluntary work (more than $3.5 \mathrm{hr}$ during the evening). All significant effects of voluntary work remained unchanged. In addition, time spent on voluntary work predicted psychological detachment from work $(\gamma=0.183 ; S E=0.077 ; t=2.38 ; p<.05)$.
} 


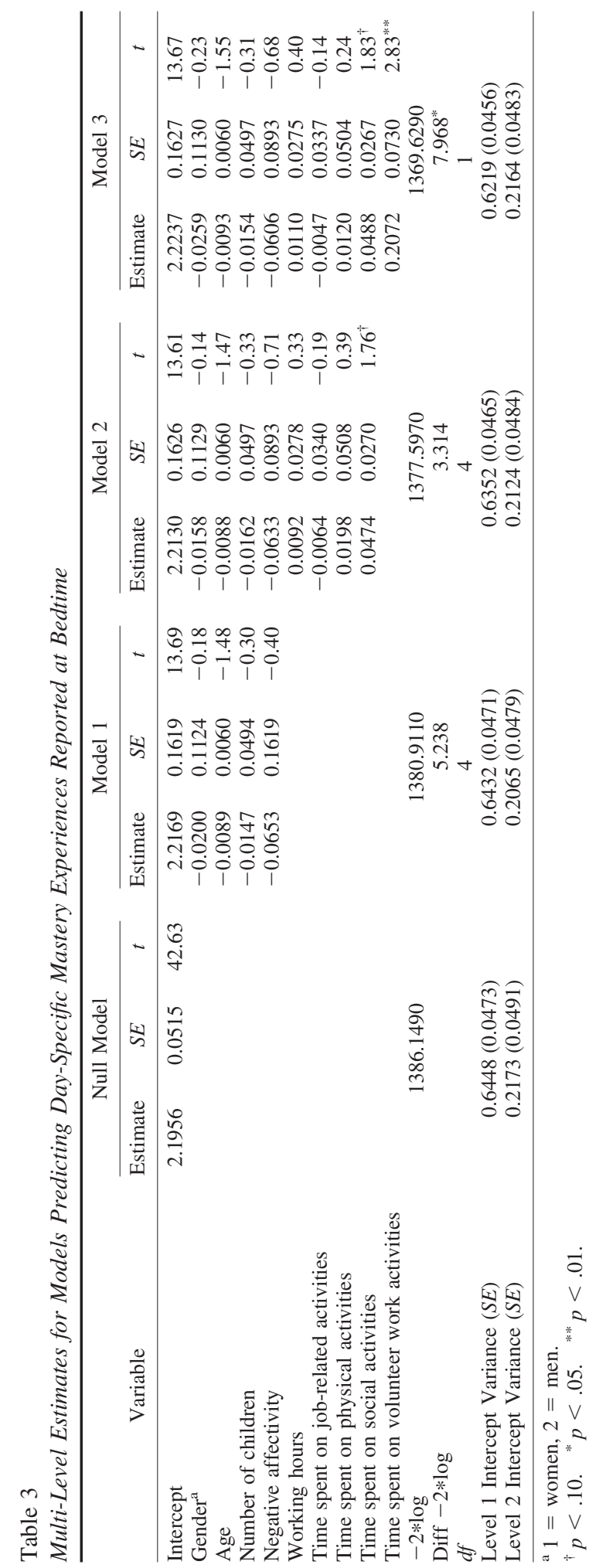




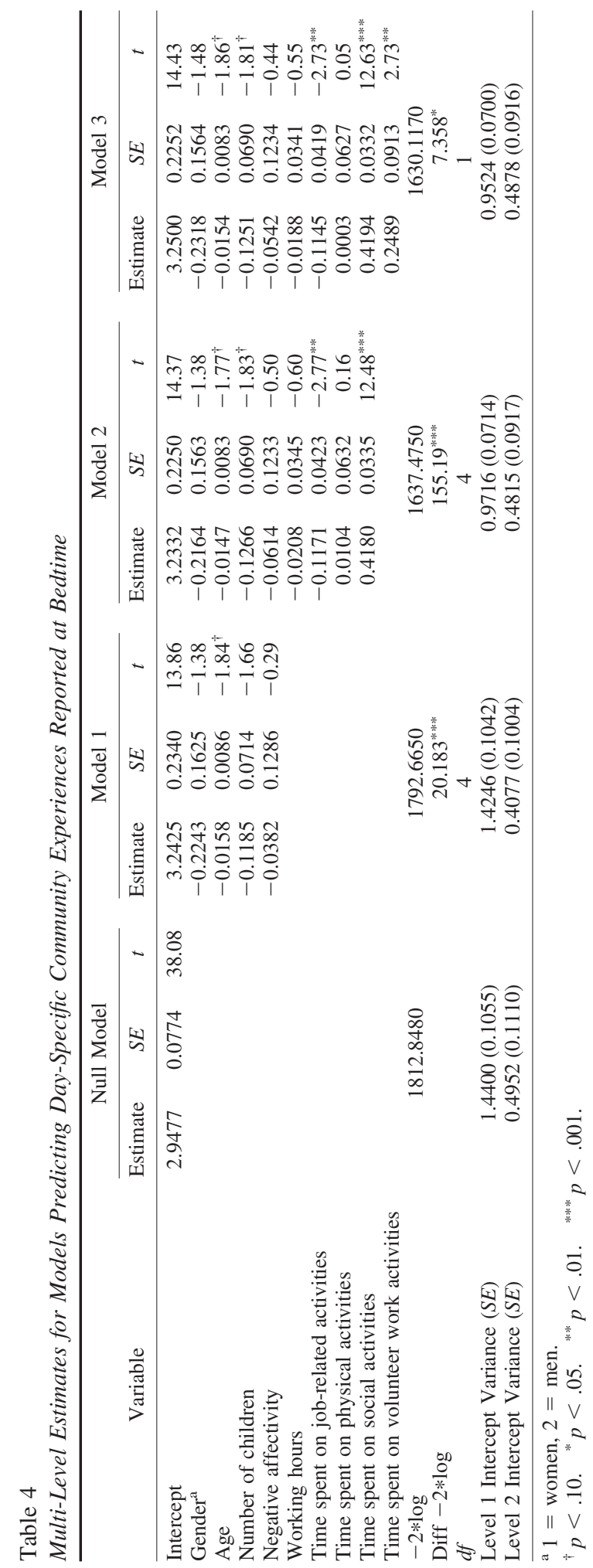


ity than the activity per se, which determines the contribution to the recovery process. Therefore, with the kind of volunteer work, as we showed positive relationships between volunteer work and mastery experiences and volunteer work and community experiences without distinguishing the type of volunteer work activity, it seems that several volunteer work activities share common characteristics that account for these positive associations. This finding is especially noteworthy, as volunteer work by itself may unfold negative effects on individual well being: volunteering can be demanding (Kinzel \& Nanson, 2000; Stebbins, 2004) and volunteer work activities are sometimes stressful (e.g., volunteering for a selfhelp group). In support of two of our hypotheses, however, we found that potentially demanding volunteer work still serves as a resource for recovery. These findings are in line with our assumption that the demands made on volunteers differ from those encountered in paid work. Another reason may be that, despite being demanding, volunteer work activities contribute to recovery that they promote the building up of new resources.

Time spent on volunteer work activities was not associated with psychological detachment from work. A possible reason why our analyses did not reveal the expected relationship is that the nature of the volunteer work activity itself may play a crucial role as to whether a person will or will not detach mentally from work. Maybe some volunteer work activities provide more opportunities for psychological detachment from work than others do, as they offer more conditions for absorption. Moreover, if a person engages in volunteer work activities that are similar to his or her regular job content, for example, a nurse volunteering as a caregiver in a hospice, it is less likely that the person will mentally detach from work. Task features of a volunteer work activity that are similar to the job can bring one's job to mind, thereby preventing psychological detachment from work.

Regarding the definition of volunteer work, it is important to add that although some authors define volunteer work as a kind of work (e.g., Bierhoff, 2002), others define it as "serious leisure time activity" (e.g., Stebbins, 1996) meaning an activity that fosters the acquisition and expression of a combination of special skills, knowledge, and experience (Stebbins, 1996). From this serious leisure time perspective taken by Stebbins (1996, 2004), we explored if volunteer work helps recovering from the working day. Thus, we tested if one kind of work (i.e., volunteer work) helps to disengage from another kind of work (i.e., paid work). The rationale was that "doing something different" (e.g., Etzion et al., 1998, p. 584) in the evening can help people to leave the working day behind. Of course, we would not deny that volunteer work itself-especially when we define it as work-may share characteristics with paid work. However, we do not believe that people need to recover from volunteer work to the same extent that they need to recover from paid work. Volunteer work, per definition, is a freely chosen activity, thus people can decide - in contrast to paid work- how much they engage in volunteer work activities, they can choose the special kind of volunteer work and they always have the possibility to change or abandon their volunteer work activities. Thus, people have a high flexibility in terms of their volunteer work activities and can adapt the degree of effort spent on volunteer work activities.

\section{Limitations and Strengths of Our Study}

Our study has some limitations that have to be taken into account when considering the results. One limitation is the lack of knowledge pertaining to the exact nature of our participants' volunteer work activities pursued during leisure time. Participants reported the amount of time spent on volunteer work on each day but did not state what they did in detail. In line with other studies which also made use of broad categories when considering leisure time activities (Sonnentag, 2001), we decided not to assess the kind of volunteer work activity in detail because we strived to keep the daily survey as short as possible to maintain our participants' motivation to answer all of the questions every day. Additionally, we assume that all volunteer work activities share common characteristics. For instance, one common characteristic of volunteer work activities is that volunteer work is freely chosen (Snyder, Omoto, \& Lindsay, 2004). Thus, despite the high variability of different volunteer work activities, it is not unlikely that the benefits of volunteer work are similar regardless of the kind of volunteer work activity. Other studies which also did not differentiate the nature of volunteer work activities also showed different volunteer work activities to be associated with similar outcomes, that is, improved well being (Thoits \& Hewitt, 2001) or job-relevant skills (Ruderman et al., 2002). Despite these reasons for our decision to operationalize volunteer work parsimoniously, we acknowledge the associated limitation concerning the quality of the activities. Therefore, we suggest for future studies to include qualitative measures of volunteer work to 
enable us to differentiate not only the kind of activity but also the idiosyncratic perception of it. Possible approaches to developing a qualitative taxonomy of volunteering activities might focus factors that motivate volunteering (such as expressing values or enhancing one's career; Clary \& Snyder, 1991; Clary et al., 1998). Another possibility to capture the quality of volunteer work would be an adaptation of the work-engagement concept (Schaufeli, Bakker, \& Salanova, 2006) to the volunteering sector. Work engagement comprises the experience of vigor, dedication, and absorption, and is potentially highly relevant within voluntary work.

Another limitation of our study is that all data were gathered by self-report measures, thereby increasing the probability of methodological biases (e.g., the social desirability bias or biased answers because of participants' implicit theories). However, we employed some statistical procedures to deal with this problem. Specifically, we centered predictor variables around the respective person's mean, thus excluding between-person variance from the predictors. It is unlikely that a person's tendency to answer questions according to social desirability or implicit theories will vary significantly across days. However, the variability across days, as opposed to the variability across individuals (who certainly do differ in their tendency to answer questions), is the key source of the examined variability in our data. Thus, the influence of individual response bias is reduced to a minimum.

Although we do acknowledge the simultaneous assessment of time spent on volunteer work and recovery experiences in self-report mode as a methodological weakness, we accepted it before the study for two reasons: First, the framing of the question was explicitly designed to activate the memory context of the leisure time activity on the given day (participants were asked to first concentrate on their activity, then categorize it, and only then indicate how they experienced it). Second, with regard to the self-report measure, it would not have been possible to gather data regarding the idiosyncratic experience of activities from external sources without introducing considerable costs to the study design. In future research, an option might be to assess recovery-related variables by means of externally gathered data, such as family or spouse ratings. Podsakoff, MacKenzie, Lee, and Podsakoff (2003) recommend this as a strategy to overcome the common method bias. However, regarding psychological detachment from work as an outcome, Sonnentag and Kruel (2006) revealed no differences in the relationships between a self-report measure of psychological detachment from work and a number of predictors on the one hand and a family report measure of psychological detachment from work and the same predictors on the other hand. This finding suggests that self-reports, as used in our study, are a valid measure of recovery.

Besides these weaknesses, our study possesses particular strengths. First, employing a diary design allowed us to assess variables of interest at the day level and to record within-person variance. Therefore, we were able to assess participants' volunteer work activity and recovery experiences with a high temporal resolution and did not require retrospective ratings from the participants, which would likely be subject to memory flaws (Bolger et al., 2003). Second, the use of handheld computers for data collection provided us with the additional opportunity to verify that the daily surveys were completed at the predefined times. Consequently, we were able to exclude those participants who completed their surveys at the wrong time (e.g., the bedtime questionnaire was filled out the next morning). This procedure contributes to the precision of our data assessment (Bolger et al., 2003).

\section{Implications for Future Research and Practice}

For future research, it seems promising to further examine relationships between volunteer work during leisure time and recovery experiences. Control during leisure time defined as a person's ability to choose an action from two or more options (Sonnentag \& Fritz, 2007) is also an important recovery experience contributing to successful recovery. Given the voluntary character of volunteer work during leisure time when considering that people choose the kind of volunteer work activity and decide when, where, and how often they engage in volunteer work activities (Snyder et al., 2004), one might expect a positive relationship between volunteer work during leisure time and control.

One practical implication pertains to the organization of working time: the positive relationships between volunteer work and mastery experiences as well as volunteer work and community experiences demand work time to be organized in a way that volunteer engagement during leisure time becomes possible. With regard to the positive associations of mastery experiences and community experiences with well being and task performance (Fritz \& Son- 
nentag, 2005; Sonnentag \& Fritz, 2007), one might even advise organizations to prepare the ground for their employees' engagement in volunteering activities. Possible ways to enable employees to private volunteering (as opposed to corporate volunteering, which is often regarded as a human resources development) without compromising its voluntary nature including measures such as granting leaves of absences or flexible work schedules (Wehner, Lorenz, \& Gentile, 2008).

Furthermore, this study also has an important implication for the individual. In line with Stebbins' (2004) statement that individuals should engage in active leisure activities, the positive relationships between volunteer work activities and the recovery experiences of mastery and community identified in this study indicate that volunteer work qualifies as such an active leisure activity. Our results add to this notion and call for a clearer and stronger focus of occupational health psychologists on volunteer work activities during leisure time as one possible contributor to an optimal leisure lifestyle (cf., Stebbins, 2004).

\section{Conclusion}

In conclusion, the overall results of our study indicate that it is interesting to focus on the power of volunteer work to build up new resources when considering antecedents of the recovery process. Most importantly, we showed that volunteer work, which until now has been widely neglected in recovery research, is positively associated with mastery experiences and community experiences. Both mastery and community experiences are important recovery experiences, and therefore offer potential to facilitate successful recovery and to contribute to a healthy leisure lifestyle.

\section{References}

Bandura, A. (1997). Self-efficacy: The exercise of control (2 ed.). New York: Freeman.

Bierhoff, H.-W. (2002). Prosocial behavior. New York: Psychology Press.

Bierhoff, H.-W., \& Schülken, T. (2001). Ehrenamtliches Engagement [Voluntary engagement]. In H.-W. Bierhoff $\&$ D. Fetchenhauer (Eds.), Solidarität. Konflikt, Umwelt und Dritte Welt [Solidarity. Conflict, environment, and Third World] (pp. 183-204). Opladen: Leske and Budrich.

Binnewies, C., Sonnentag, S., \& Mojza, E. J. (2009b). Feeling recovered and thinking about the good sides of one's work. A longitudinal study on the benefits of non-work experiences for job performance. Journal of Occupational Health Psychology, 14, 243-256.

Bolger, N., Davis, A., \& Rafaeli, E. (2003). Diary methods: Capturing life as it is lived. Annual Review of Psychology, 54, 579-616.

Brief, A. P., Burke, M. J., George, J. M., Robinson, B. S., \& Webster, J. (1988). Should negative affectivity remain an unmeasured variable in the study of job stress? Journal of Applied Psychology, 73, 193-198.

Clary, E. G., \& Snyder, M. (1991). A functional analysis of altruism and prosocial behavior. The case of volunteerism. In M. S. Clark (Ed.), Prosocial behavior (pp. 119148). Newbury Park, CA: Sage.

Clary, E. G., Snyder, M., Ridge, R. D., Copeland, J., Stukas, A. A., Haugen, J., et al. (1998). Understanding and assessing the motivations of volunteers: A functional approach. Journal of Personality and Social Psychology, 74, 1516-1530.

Cropley, M., Dijk, D.-J., \& Stanley, N. (2006). Job strain, work rumination, and sleep in school teachers. European Journal of Work and Organizational Psychology, 15, 181-196.

Cropley, M., \& Millward Purvis, L. J. (2003). Job strain and rumination about work issues during leisure time: A diary study. European Journal of Work and Organizational Psychology, 12, 195-207.

Csikszentmihalyi, M. (1990). Flow. The psychology of optimal experience. New York: HarperCollins Publishers.

Etzion, D., Eden, D., \& Lapidot, Y. (1998). Relief from job stressors and burnout: Reserve service as a respite. Journal of Applied Psychology, 83, 577-585.

Fritz, C., \& Sonnentag, S. (2005). Recovery, health, and job performance: Effects of weekend experiences. Journal of Occupational Health Psychology, 10, 187-199.

Fritz, C., \& Sonnentag, S. (2006). Recovery, well-being, and performance-related outcomes: The role of work load and vacation experiences. Journal of Applied Psychology, 91, 936-945.

Hobfoll, S. E. (1989). Conservation of resources. American Psychologist, 44, 513-524.

Kinzel, A., \& Nanson, J. (2000). Education and debriefing: Strategies for preventing crisis in crisis-line volunteers. Crisis, 21, 126-134.

Krohne, H. W., Egloff, B., Kohlmann, C.-W., \& Tausch, A. (1996). Untersuchungen mit einer deutschen Version der "Positive and Negative Affect Schedule" (PANAS) [Investigations with a German version of the PANAS]. Diagnostica, 42, 139-156.

Meijman, T. F., \& Mulder, G. (1998). Psychological aspects of workload. In P. J. D. Drenth, H. Thierry, \& C. J. de Wolff (Eds.), Handbook of work and organizational psychology (Vol. 2, pp. 5-33). East Sussex, UK: Psychology Press Ltd.

Podsakoff, P. M., MacKenzie, S. B., Lee, J.-Y., \& Podsakoff, N. P. (2003). Common method biases in behavioral research: A critical review of the literature and recommended remedies. Journal of Applied Psychology, 88, 879-903.

Rasbash, J., Steele, F., Browne, W., \& Prosser, B. (2004). A user's guide to MLwiN (2 Ed.). London, UK: Centre for Multilevel Modeling, Institute for Education, University of London.

Reis, H. T., Sheldon, K. M., Gable, S. L., Roscoe, J., \& Ryan, R. M. (2000). Daily well-being: The role of au- 
tonomy, competence, and relatedness. Personality and Social Psychology Bulletin, 26, 419-435.

Rook, J. W., \& Zijlstra, F. R. H. (2006). The contribution of various types of activities to recovery. European Journal of Work and Organizational Psychology, 15, 218-240.

Ruderman, M. N., Ohlott, P. J., Panzer, K., \& King, S. N. (2002). Benefits of multiple roles for managerial women. Academy of Management Journal, 45, 369-386.

Schaufeli, W. B., Bakker, A. B., \& Salanova, M. (2006). The measurement of work engagement with a short questionnaire: A cross-national study. Educational and Psychological Measurement, 66, 701-716.

Schroer, J., \& Hertel, G. (2009). Voluntary engagement in an open web-based encyclopedia: Wikipedians, and why they do it. Media Psychology, 12, 96-120.

Sheldon, K. M., Ryan, R., \& Reis, H. T. (1996). What makes for a good day? Competence and autonomy in the day and in the person. Personality and Social Psychology Bulletin, 22, 1270-1279.

Snyder, M., Omoto, A. M., \& Lindsay, J. J. (2004). Sacrificing time and effort for the good of others. In A. G. Miller (Ed.), The social psychology of good and evil (pp. 444-468). New York: The Guilford Press.

Sonnentag, S. (2001). Work, recovery activities, and individual well-being: A diary study. Journal of Ocсираtional Health Psychology, 6, 196-210.

Sonnentag, S., \& Bayer, U.-V. (2005). Switching off mentally: Predictors and consequences of psychological detachment from work during off-job time. Journal of Occupational Health Psychology, 10, 393-414.

Sonnentag, S., Binnewies, C., \& Mojza, E. J. (2008). Did you have a nice evening? A day-level study on recovery experiences, sleep, and affect. Journal of Applied Psychology, 93, 674-684.

Sonnentag, S., \& Fritz, C. (2007). The recovery experience questionnaire: Development and validation of a measure for assessing recuperation and unwinding from work. Journal of Occupational Health Psychology, 12, 204221.

Sonnentag, S., \& Kruel, U. (2006). Psychological detachment from work during off-job time: The role of job stressors, job involvement, and recovery-related selfefficacy. European Journal of Work and Organizational Psychology, 15, 197-217.

Sonnentag, S., \& Natter, E. (2004). Flight attendants' daily recovery from work: Is there no place like home? International Journal of Stress Management, 11, 366-391.

Stebbins, R. A. (1996). Volunteering. A serious leisure perspective. Nonprofit and Voluntary Sector Quarterly, $25,211-224$.

Stebbins, R. A. (2004). Serious leisure, volunteerism and quality of life. In J. T. Haworth \& A. J. Veal (Eds.), Work and leisure (pp. 200-212). London and New York: Routledge.

Taris, T. W., Geurts, S. A. E., Schaufeli, W. B., Blonk, R. W. B., \& Lagerveld, S. E. (2008). All day and all of the night: The relative contribution of two dimensions of workaholism to well-being in self-employed workers. Work \& Stress, 22, 153-165.

Thoits, P. A., \& Hewitt, L. N. (2001). Volunteer work and well-being. Journal of Health and Social Behavior, 42, $115-131$.

TNS Infratest. (2007). Drei von zehn Europäern leisten ehrenamtliche Arbeit [Three out of ten Europeans engage in volunteer work]. Retrieved February 27, 2009, from http:// www.tns-infratest.com/suchergebnisse.asp

Totterdell, P., \& Parkinson, B. (1999). Use and effectiveness of self-regulation strategies for improving mood in a group of trainee teachers. Journal of Occupational Health Psychology, 4, 219-232.

United States Department of Labor. (2009). Volunteering in the United States 2008. Retrieved February 27, 2009, from http://www.bls.gov/news.release/volun.nr0.htm

von Rosenbladt, B. (2000). Freiwilliges Engagement in Deutschland [Voluntary engagement in Germany]. Stuttgart: Kohlhammer.

Watson, D., Clark, L. A., \& Tellegen, A. (1988). Development and validation of brief measures of positive and negative affect: The PANAS scales. Journal of Personality and Social Psychology, 54, 1063-1070.

Wehner, T., Lorenz, C., \& Gentile, G.-C. (2008). Corporate volunteering: Das hohe $\mathrm{C}$ der unternehmerischen Verantwortung. Potenziale und Herausforderungen [Corporate volunteering. The high $\mathrm{C}$ of corporate responsibility. Potentials and challenges.]. Zeitschrift Führung $+\mathrm{Or}$ ganisation, 77, 352-359.

Wilson, J. (2000). Volunteering. Annual Review of Sociology, 26, 215-240.

Wilson, J., \& Musick, M. (2003). Doing well by doing good: Volunteering and occupational achievement among American women. Sociological Quarterly, 44, 433-450.

Zijlstra, F. R. H., \& Cropley, M. (2006). Recovery after work. In F. Jones, M. J. Burke, \& M. Westman (Eds.), Work-life balance: A psychological perspective. (pp. 219-234). East Sussex, UK: Psychology Press.

Received August 18, 2008

Revision received July 30, 2009

Accepted August 3, 2009 